Article

\title{
Integrating Parametric Analysis with Building Information Modeling to Improve Energy Performance of Construction Projects
}

\author{
Mohammad K. Najjar ${ }^{1} * \mathbb{E}$, Vivian W. Y. Tam ${ }^{2}$ (D) Leandro Torres Di Gregorio ${ }^{1}$, \\ Ana Catarina Jorge Evangelista ${ }^{3}(\mathbb{D})$, Ahmed W. A. Hammad ${ }^{4}$ and Assed Haddad 1,*(D) \\ 1 Program de Engenharia Ambiental, Universidade Federal do Rio de Janeiro, Rio de Janeiro 21941-901, Brazil; \\ leandro.torres@poli.ufrj.br \\ 2 School of Computing, Engineering and Mathematics, Western Sydney University, \\ Penrith, NSW 2751, Australia; vivianwytam@gmail.com \\ 3 School of Computing, Engineering and Mathematics, Western Sydney University, \\ Penrith, NSW 2751, Australia; ana.evangelista@westernsydney.edu.au \\ 4 Faculty of Built Environment, New South Wales University, Sydney, NSW 2052, Australia; \\ a.hammad@unsw.edu.au \\ * Correspondence: mnajjar@poli.ufrj.br (M.K.N.); assed@poli.ufrj.br (A.H.)
}

Received: 27 March 2019; Accepted: 9 April 2019; Published: 22 April 2019

\begin{abstract}
Buildings demand a significant amount of energy during their life cycles, hence, effective design measures need to be adopted to ensure efficient energy usage and management in buildings. This study proposes a framework based on various performance parameters to enable decision-makers utilizing standard procedures and software to empower the process of sustainable energy use and management in buildings, through a parametric analysis in different climatic conditions. Experimental design is adopted within the framework via the use of various performance parameters related to the building design (i.e., construction materials for exterior walls and roofs, as well as a set of window-to-wall ratios). Results indicate that climate data plays a fundamental role in the choice of design factors that are best suited for effective energy consumption in buildings. In particular, sub-type climate classifications, as opposed to the primary climate group, have a minor influence. Around 15\% improvement in the energy consumption in buildings is noticed due to changes to the design factor such as the window-to-wall ratio. Insights that can be gleaned from this study include the impact of space area, exterior openings and material thickness and choice for the envelope of the building in all climate classifications, aiding in the design of low-energy buildings.
\end{abstract}

Keywords: energy in buildings; building management; building information modeling; sustainable construction; experimental design

\section{Introduction}

The construction industry consumes significant energy and natural resource levels and is commonly known as "the industry of the $40 \%$ " [1], due to the fact that buildings produce nearly $40 \%$ of overall $\mathrm{CO}_{2}$ emissions, $40 \%$ of overall waste generation and consume $40 \%$ of overall natural resources over their entire lifespans [2]. The world is witnessing an increase in awareness with regards to enhanced energy efficiency in construction [3,4], specifically due to the fact that the majority of the energy in the construction sector is consumed during the operating phase of buildings (i.e., for heating, cooling, lighting and hot water equipment) [5]. As a result, modeling energy performance is a critical issue to perform and manage the energy efficiency in buildings [6,7]. Several tools and methods have been assessed to support the implementation of sustainable strategies in the built environment. In particular, 
Building Information Modeling (BIM) has been proposed as an innovative approach with many useful tools that can effectively evaluate energy performance in buildings [8], by harmonizing information of building material and facilitating the calculation of their environmental impacts [9].

Some factors play an important role in determining the energy-use patterns in buildings, such as building type, climate zone and level of economic development [10]. BIM offers the opportunity to save time that is consumed by designers, engineers and architects to account for all building geometry and the necessary information to complete an energy analysis [11,12]. The collected results at this level of the analysis include statistics related to energy use and breakdowns of consumption and loads [13]. Furthermore, BIM plays a fundamental role in automation in construction [14]; various dimensions of $\mathrm{BIM}(\mathrm{nD})$, including cost and time control, design and simulation enable effective building control over the entire life-cycle phase of construction projects [15].

A current gap exists in the literature for utilizing BIM as an approach that aids designers in adopting a strategic energy-use plan over the operation phase of buildings. As a result, the novelty of the research presented herein is to propose a framework that integrates different performance parameters, such as the building design, climate data, along with design factors, including building components, energy use and consumption, utilizing 3D modeling and sustainability as $\mathrm{nD}$ BIM dimensions in order to improve the energy performance of buildings. The aim is to make the work readily available to practitioners and experts in the construction sector using standard procedures and software. It is envisaged that the proposed method will empower the decision-making processes and sustainability of designing construction projects. The Energy Use Intensity (EUI) is evaluated, taking into consideration the building components that comprise the envelop of buildings, relevant measures including the window-to-wall ratio and of the energy consumed for heating, cooling, lighting and equipment purposes.

Throughout this study, the proposed framework involves incorporating different design parameters and visualization-aid tools that prove the ability to improve energy performance in buildings. Enhancing the energy performance in construction projects is conducted through a simulation and parametric analysis approach, where the construction materials of exterior walls and the roof of a building, as well as a set of window-to-wall ratios, are all examined. An experimental design, which involves a systematic collection of data, is utilized to focus on the planning of the selection process of construction materials, based on a linear regression analysis [16]. The methodological framework developed accommodates various global climates, in response to the consensus worldwide on the need for improving energy consumption in buildings and enhancing the sustainability of the built environment. The tools of BIM are applied to evaluate and improve the energy performance towards low-energy buildings using simulation data and sustainability as BIM dimensions. A case study of a single-family house is examined in six cities with varying climate data and annual average temperature to validate the developed methodological framework.

This paper is organized as follows: in Section 2, some background on BIM and its use for sustainable design are presented. Next, in Section 3, the methodology of this work is explained in detail, while Section 4 illustrates the linking of the framework's components. In Section 5, a case study is examined to validate the proposed methodology.

\section{Background}

\subsection{BIM Dimensions}

In the BIM approach, the modelling is multidimensional. In fact, it incorporates all required design information over the entire life span of construction projects. The so-called BIM n-D models are commonly defined as shown in Figure 1: 3D modeling, 4D (Time), 5D (Cost), 6D (Operation), 7D (Sustainability) and 8D (Safety) [17]. 


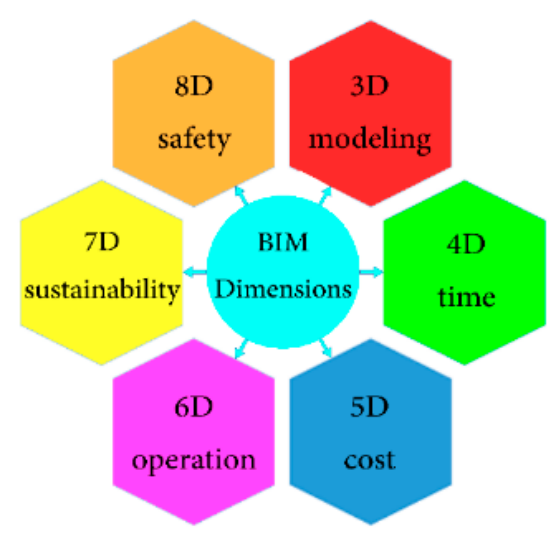

Figure 1. Building Information Modeling (BIM) dimensions.

3D BIM is the most familiar dimension adopted for the designing process of creating graphical and non-graphical information that is shared in a common data environment [17]. The level of importance of this dimension peaks at the planning and designing phase of the construction project, then it reduces gradually until the end of the operation and maintenance phase, as seen in Figure 2. This comes back to the fact that such dimension enables providing various design alternatives at this phase of the project life cycle [18]. 4D dimension is a planning process that binds the set of data in the 3D modeling with project programming and scheduling data [17]. It accelerates the simulation analysis of construction activities $[19,20]$. Hence, the important role of this dimension starts at a point somewhere at the designing phase, peaks during the construction phase, before reducing gradually during the next life cycle phases of construction projects, as seen in Figure 2. Such a dimension provides an opportunity for participants of a construction project to effectively visualize, analyze and communicate various aspects of construction progress over the entire life span of buildings. 5D dimension integrates $4 \mathrm{D}$ dimension with cost data such as quantities and prices [17]. It facilitates the accuracy of both quantity and cost estimation $[19,21]$. The important role of this dimension grows gradually from the starting point of the planning and designing phase, peaks during the construction phase, then reduces during the operation and end-of-life phases, as seen in Figure 2. Such a dimension provides an opportunity for cost consultants to improve the value of construction projects. $6 \mathrm{D}$ dimension extends BIM for facilities management [17], which is considered an integrated approach to maintain, improve and adapt buildings [22]; this dimension represents the as-built model that is used during the operational phase of construction projects [23], providing an opportunity for an integrated description of a building during its usage phase. The important role of this dimension starts by the end of the construction phase and lasts over the entire operation and maintenance phase of construction projects, as shown in Figure 2. 7D dimension incorporates components of sustainability within BIM [17]; the different BIM dimensions are stored in a "BIM knowledge repository" [24]. At this level of the analysis, 3D, 4D and 5D BIM dimensions enable designers to compare different alternatives, make a quick modification of building modeling and management and validate the decision-making towards meeting the sustainable requirements of construction projects [24]. Such requirements can be achieved during the designing and construction phases of construction projects, while the chance to meet the sustainability requirements reduces gradually in the next life cycle phase until it ends up at a point somewhere during this phase, as shown in Figure 2. 8D dimension incorporates different aspects of safety in construction projects during the designing and construction phases [17], as shown in Figure 2. To sum up, BIM provides an opportunity to optimize, simulate and visualize building design and therefore deliver high quality construction documentations [14]. Figure 2 illustrates the level of importance of BIM dimensions over the entire life span of construction projects. 


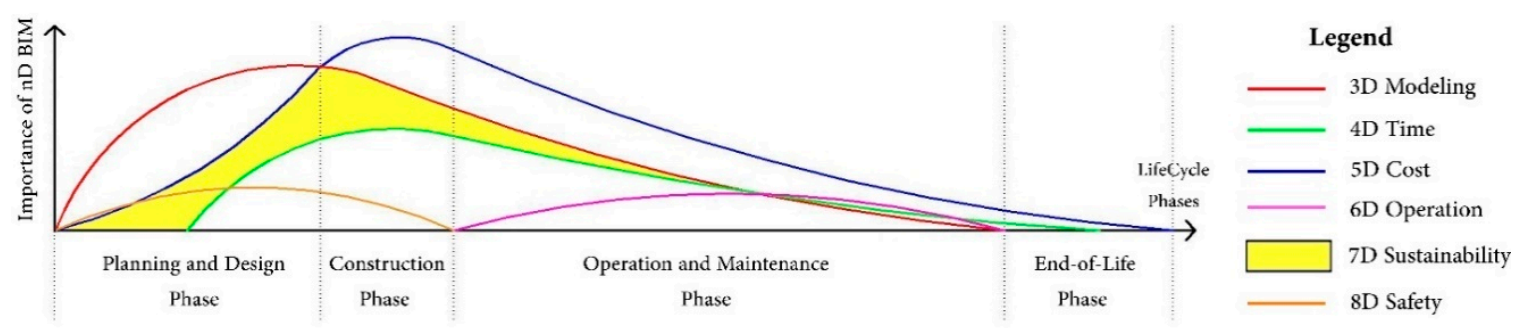

Figure 2. Level of importance of BIM dimensions over the entire life-cycle phases.

\subsection{Climate Zone Classification}

Climatic conditions are known to impact the energy performance of a building $[25,26]$. There are several schemes to classify climates into similar regimes such as plant hardiness, evapotranspiration and Köppen-Geiger climate classification, being the one that is the most widely applied to classify climate zones $[27,28]$. Köppen classification scheme analyzes average monthly temperature and precipitation for 1901-2010 at all grid points on Earth. It divides climate zones into five major groups, namely Tropical Climates (A), Dry Climates (B), Mild Temperate Climates (C), Continental Climates (D) and Polar Climates (E) [29,30]. According to the Köppen-Geiger classification scheme, such five major climate groups are subdivided into 31 sub-types [29-32]:

A. Tropical Climates, which is covering more than $20 \%$ of surface area, is subdivided into Tropical rainforest climate (Af), Tropical monsoon climate (Am) and Tropical savanna climate (Aw or As). The average temperature of the coldest month of the year for Tropical Climates is more than $18^{\circ} \mathrm{C}$.

B. Dry Climates, which is covering more than $27 \%$ of surface area, is subdivided into Hot desert climate (BWh), Cold desert climate (BWk), Hot semi-arid climate (BSh) and Cold semi-arid climate (BSk). The average annual temperature for Dry Climates is between 20 and $35^{\circ} \mathrm{C}$.

C. Mild Temperate Climates, which is covering more than $15 \%$ of the surface area, is subdivided into Humid subtropical climate (Cfa), Temperate oceanic climate (Cfb), Subpolar oceanic climate (Cfc), Monsoon-influenced humid subtropical climate (Cwa), Subtropical highland climate $(\mathrm{Cwb})$, Cold subtropical highland climate (Cwc), Hot-summer Mediterranean climate (Csa), Warm-summer Mediterranean climate (Csb) and Cool-summer Mediterranean climate (Csc). The average annual temperature for Mild Temperate Climates is between -3 and $18^{\circ} \mathrm{C}$.

D. Continental Climates, which is covering more than $21 \%$ of the surface area, is subdivided into Hot-summer humid continental climate (Dfa), Warm-summer humid continental climate (Dfb), Subarctic climate (Dfc), Extremely cold subarctic climate (Dfd), Monsoon-influenced hot-summer humid continental climate (Dwa), Monsoon-influenced warm-summer humid continental climate (Dwb), Monsoon-influenced subarctic climate (Dwc), Monsoon-influenced extremely cold subarctic climate (Dwd), Mediterranean-influenced hot-summer humid continental climate (Dsa), Mediterranean-influenced warm-summer humid continental climate (Dsb), Mediterranean-influenced subarctic climate (Dsc) and Mediterranean-influenced extremely cold, subarctic climate (Dsd). The average annual temperature is less than $-3^{\circ} \mathrm{C}$.

E. Polar Climates, which is covering up to $16 \%$ of the surface area, is subdivided into Tundra climate (ET) and Ice cap climate (EF). The lowest temperature ever recorded is $-89.2{ }^{\circ} \mathrm{C}$.

\subsection{Related Literature}

BIM as an approach can be utilized in the construction sector to increase the energy performance of construction projects and, consequently, enhance the sustainability of the built environment $[8,11]$. In the literature, several publications examined the important role of BIM towards achieving the objectives of construction projects. For example, Azhar and Brown [33] highlighted and investigated the viability of BIM towards sustainable design. The authors collected data via a questionnaire survey, 
a case study and semi-structured interviews in order to identify the benefits of BIM in the field of sustainability analysis; this was achieved by evaluating different software that analyzes building performance and developing a conceptual framework to incorporate BIM and Life Cycle Assessment in the field of sustainability analysis. Jeong and Son [34] presented an algorithm that translates the BIM building topology into an object-oriented physical using an object-oriented programming approach. GhaffarianHoseini et al. [14] focused on energy efficiency in buildings. The authors reviewed 96 papers and suggested a system called Integrated Knowledge-based Building Management System (BIM-IKBMS) using $\mathrm{nD}$ BIM applications in order to advance the successful implementation of sustainable building performances during the post-construction building lifecycle. Azhar et al. [35] examined the ability of BIM to empower sustainable building design and decision-making processes. They found that BIM optimizes building design and performs complex building analysis. In addition to this, BIM generates the necessary documentation for Leadership in Energy and Environmental Design (LEED), which is a green building rating system applied in the USA and saves considerable time and resources as a result.

Chong et al. [36] examined the ability of BIM development for sustainability. The authors found that there are insufficient works in the field of BIM application at the refurbishment and demolition phases. Besides, it was concluded that: (i) assessing sustainability criteria requires new tools of BIM; (ii) the integration between BIM software and energy simulation tools needs to be improved; (iii) the efficient steps are required to apply BIM into various aspects of refurbishment and demolition phases successfully; and (iv) the innovative system is required to adapt social sustainability into the project. Ilhan and Yaman [37] integrated BIM and sustainable data model for the designing stage of a construction building, considering Industry Foundation Classes (IFC) that is the main standard for BIM. The authors presented GBAT as a Green Building Assessment Tool to extract the green rating score table based on BREEAM (Building Research Establishment Environmental Assessment Method) applied on materials, inform the design and provide feedback for further evaluation. Azhar et al. [38] considered that BIM increases the productivity and quality of construction projects. The authors discussed the benefits of BIM by presenting two case studies demonstrating the different tangible and intangible benefits that could be achieved by all stakeholders in the Architecture, Engineering and Construction (AEC) industries.

As can be noticed from the literature, even though the applicability of BIM for sustainable analysis and design of buildings was discussed, there is still a lack of methods in developing large energy efficient projects, given the limited availability of data and materials [39]. Hence, this work aims to propose a framework that could aid the practitioners in the construction sector to accommodate various construction components that compose the building envelop to improve the energy efficiency of buildings, hence leading to low-energy building construction projects.

The focus of the proposed method is placed on examining the design requirements in buildings, considering the EUI as a helpful metric to benchmark the energy performance based on design goals in buildings [40]. As a result, this work provides an integrated and systematic methodological framework to improve energy efficiency in buildings that aligns with the environmental conditions and demand expectations of a given building project. In this section, an in-depth explanation of the EUI, design requirements and decision support analysis are presented.

EUI articulates the energy efficiency in buildings as a function of its size or other characteristics such as the building function and occupation density and daily and yearly using periods [41]. It is expressed as energy per square meter per year and is calculated by dividing the total energy consumed by the building in one year by the total gross floor area of the building [42,43]. The current focus on increasing energy use efficiency in buildings has made the use of EUI popular by governmental organizations, non-government organizations and building industry groups, including American Society of Heating, Refrigerating and Air-Conditioning Engineers (ASHRAE) [40]. Figure 3 gives an example of the calculation process of EUI in residential buildings, highlighting that the energy consumed in buildings could be the result of heating, cooling, lighting, equipment, pumps and hot water requirements. Energy consumption in buildings certainly depends on the type of building itself; 
low values of EUI signifies good levels of energy efficiency measures implemented in the building under consideration [44]. It is important that the domestic appliances that will consume energy are considered early on, at the design phase of construction projects; designers have to realize the energy impacts of the heating, cooling, lighting and other equipment that will be installed and used by the occupants [5]. Some methods have been proposed to reduce EUI in buildings. For instance, ensuring the proper maintenance of equipment to improve the efficiency of operation, installing motion activated lights or occupancy sensors, incorporating the use of natural sunlight into the design of occupied spaces, providing a means for passive heating and cooling of interior spaces and developing on-site renewable energy generation [44].

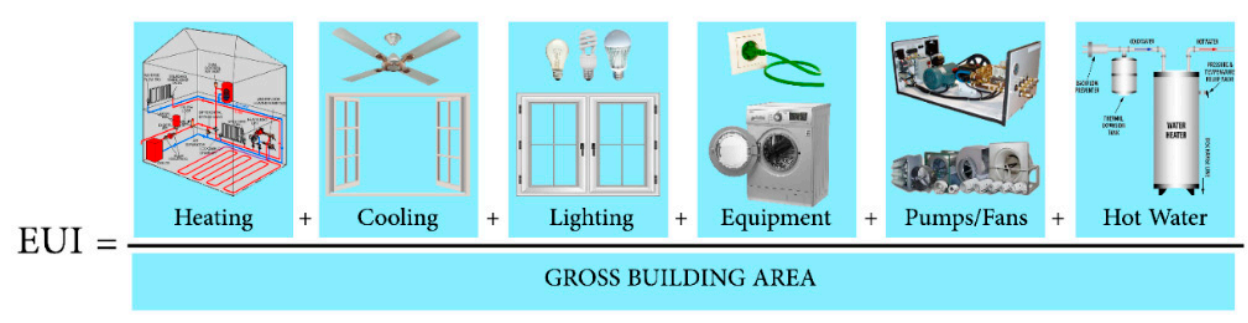

Figure 3. Energy use intensity in residential buildings.

In the next section, the design requirements for sustainable construction and the decision-support analysis are demonstrated within the full framework proposed.

\section{Materials and Methods}

The methodology proposed in this paper simulates the energy performance of construction projects, through integrating parametric analysis with BIM approach.

\subsection{Design Requirements for Sustainable Construction}

Construction projects are increasingly constrained by a set of functional requirements that result from higher standards of living [45]. In literature, the design requirements for sustainable construction are outlined in three basic analysis [46,47]; energy analysis, architectural analysis and comfort analysis, as seen in Figure 4. In these terms, designing for better energy performance is one of the key issues of sustainable construction $[4,48]$, which involves a holistic approach to energy consumption and emissions to encourage environmental friendliness in buildings [49]. This way of creating buildings that are energy efficient [32,49], appropriately and architecturally designed for their context of use [50] and comfortable for occupation by people [51]. The majority of energy consumption in buildings is caused by heating, cooling and lighting purposes [52]. For example, the consumption of electricity is the main agent of high levels of $\mathrm{CO}_{2}$ emissions in buildings [53]. Second, architectural analysis refers to predicting post-occupancy performance in buildings at an early stage of design, to optimize the project and understand the required decisions that could significantly affect the carbon footprint of buildings [54]. This involves studying the building form and typology within the built environment, considering the interaction of people and the evolution of the concept of building design from the first conception to production [55]. Third, comfort analysis means to raise the issue of a sustainable environment by expressing satisfaction with the thermal environment and is estimated by subjective evaluation [56]. 


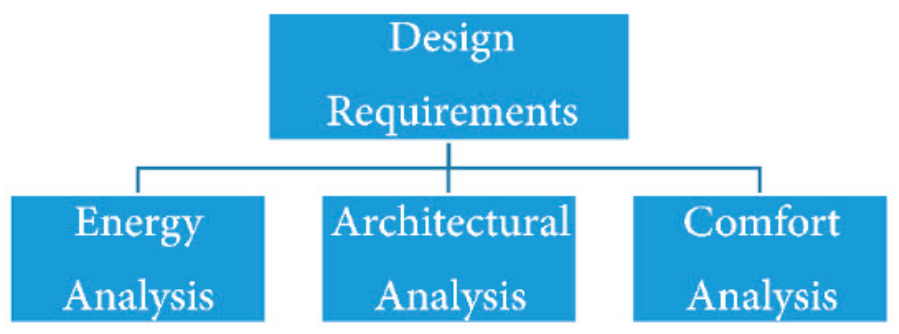

Figure 4. Design requirements for sustainable construction.

\subsection{Decision Support Analysis}

BIM is an approach that enables the creation of intelligent models used to design and manage buildings and cooperate the designing process [57]. Such approach can significantly reduce the opportunities for errors when revising or modifying the model information [58]. The initial step in the developed approach requires the input of a 2D and 3D model of the building. This way of defining the parameters that are influencing the consumption of energy during the operation phase of the building such as building properties (i.e., space area and basic appliances), type of energy use and define the building components. In addition to this, it requires classifying the climate database of the region where the construction project is to be constructed. Figure 5 highlights the developed framework in this study, which links performance parameters and design factors.

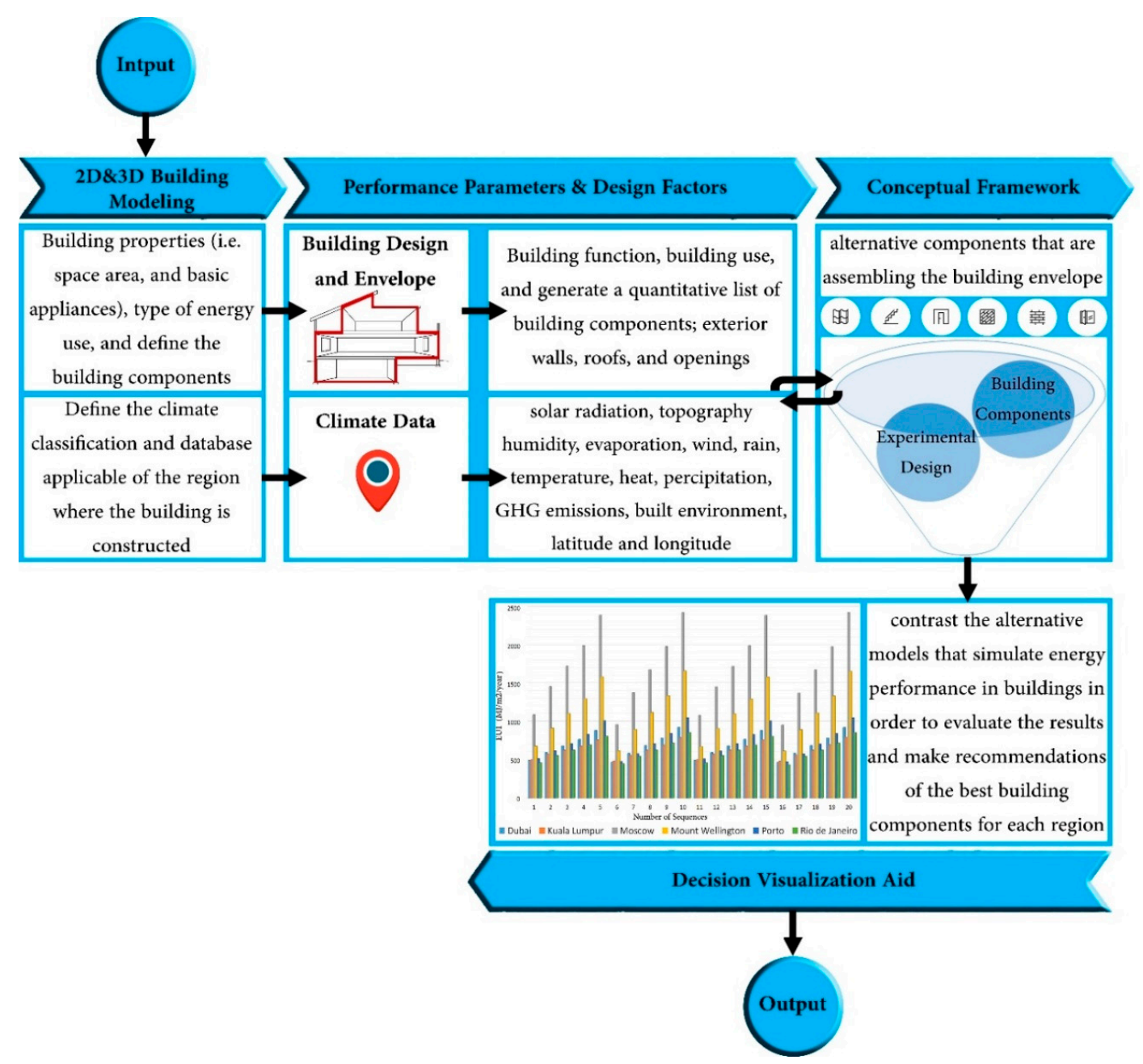

Figure 5. A methodological framework for increasing energy performance in construction projects. 
The modeling of buildings requires identifying various performance parameters and their associated design factors. Performance parameters refer to the information that defines and classify a particular system in the model, while design factors are features (variables) that define the performance parameters, as depicted in Figure 5. The choice of performance parameters is based on implications that are highly affecting the energy consumption of construction projects, namely the building design and envelope $[59,60]$, along with the climate classification in which the building is located $[25,26]$. Climate data as a performance parameter, the associated design features include solar radiation, topography, humidity, evaporation, wind, rain, temperature, heat, precipitation, greenhouse gas (GHG) emissions, built environment, latitude and longitude [61,62]. The features of the performance parameter Building Design and Envelope include identifying the function, use of the building and generate a quantitative list of building components that are assembling the building envelope such as exterior walls, roofs and openings of the building $[40,63]$. In these terms, the proposed methodological framework of this analysis can accommodate a large number of construction components, however, some specific components are chosen in the case study, Section 5, just to validate the framework.

The next step is to define the conceptual framework of the study. It starts by assessing the collected data using the indicators of sustainability in a way to empower the decision-making process. Conducting this step requires make reliable information that are simpler and available to policy makers. However, the evaluation process of the collected database starts by enrolling all or part of the generated building components of the construction project and estimating the consumption of energy, using BIM approach as a platform for quantifying the sustainability in buildings. The methodology of this study makes use of an experimental design procedure to identify all the expected variables in order to indicate the best building components and effective window-to-wall ratios that will improve energy efficiency in buildings, based on different climate data and annual average temperatures.

The experimental design work is applied via linear regression that defines the impact of several design factors and a parametric analysis that examines different values for these factors. The experimental design provides the maximum information at the minimum experimental cost [64]. Hence, this work evaluates and generates the variables collected at the experimental design phase, in BIM-related tools in order to integrate the construction of buildings and consequently achieve the objectives of the study. The last step of the methodological framework of this study is to assess the output results. At this level of the analysis, this work recommends contrasting the alterative models that simulate the energy performance in construction projects in a way to analyze and evaluate the collected results and define the best construction components that could improve the energy efficiency in buildings. This process starts by classifying sources of data, comparing and matching results and suggesting recommendations.

\section{Linking Framework Components}

In terms of the required analysis, three basic steps are required to improve the energy performance in buildings, as shown in Figure 6. The first step is to identify the performance parameters and the design factors of the construction project, which means identifying the building design and climate data. For this work, Autodesk Revit is applied as a BIM software to achieve the aim of this step by creating a BIM model and considering the database of the various climate classifications. The climate server in Revit enables climate database from several sources such as Green Building Studio weather station, which accommodates around 1.6 million virtual weather stations and allows better and accurate climate simulations [65].

The second step is to build up the inventory of the database. The proposed framework applies the experimental design to estimate all expected variables via linear regression. At this level of the analysis, the interaction effects are found by the use of a statistical factorial design technique [66]. This requires running a full complement of all possible factor combinations of the components of the building envelop, as a basic parameter influencing energy performance in buildings [59]. Interaction effects between components that define the number of factors ( $\kappa$ ) (i.e., window-to-wall ratio, building components, etc.) and the desired range of their investigated levels that could influence the overall 
EUI are also investigated [67]. In these terms, a factorial design model in this study is analyzed via regression analysis and is presented in Equation (1) to allow the estimation of all coefficients $\left\{\beta_{0}, \ldots\right.$, $\left.\beta_{\kappa}\right\}[68,69]$.

$$
Y=\beta_{0}+\beta_{1} \cdot \chi_{1}+\beta_{2} \cdot \chi_{2}+\ldots+\beta_{\kappa} \cdot \chi_{\kappa}+\epsilon
$$

Equation (1) calculates all the actual responses and interactions of the expected variables [69]; in the experimental design, errors are inevitable [70]. As a result, the second step is conducted in two phases. The first phase is to use a software namely, Minitab to determine all the variables of the experimental design work through a linear regression analysis and reduce the regression errors and uncertainty [71]. The second phase involves adopting the tools of BIM to simulate the determined variables and estimate the energy performance in buildings. This work uses Autodesk Green Building Studio as a BIM tool to assess the sustainability of the design [72]. The analysis requires taking into consideration the different assumptions and parameters that are required to be filled-in precisely such as building type, location, thermal properties, project phase, building envelope, analysis mode, conceptual construction, building operating schedule, HVAC system (Heating, Ventilation and Air Conditioning) and outdoor air information. The third step is to evaluate the collected database for each modeling. At this level of the analysis, the collected EUI results in Autodesk Green Building Studio are evaluated in order to specify the impact of building components and window-to-wall ratio on energy consumption in buildings [73]. Conducting such an analysis demands a parametric analysis involving gradual increments of the window-to-wall ratio and various building components. Furthermore, Minitab software conducts the main effects plot, as presented in the supplementary file, by creating graphs that use data means. This analysis is vital for examining the differences between levels for one or more design factor [74].

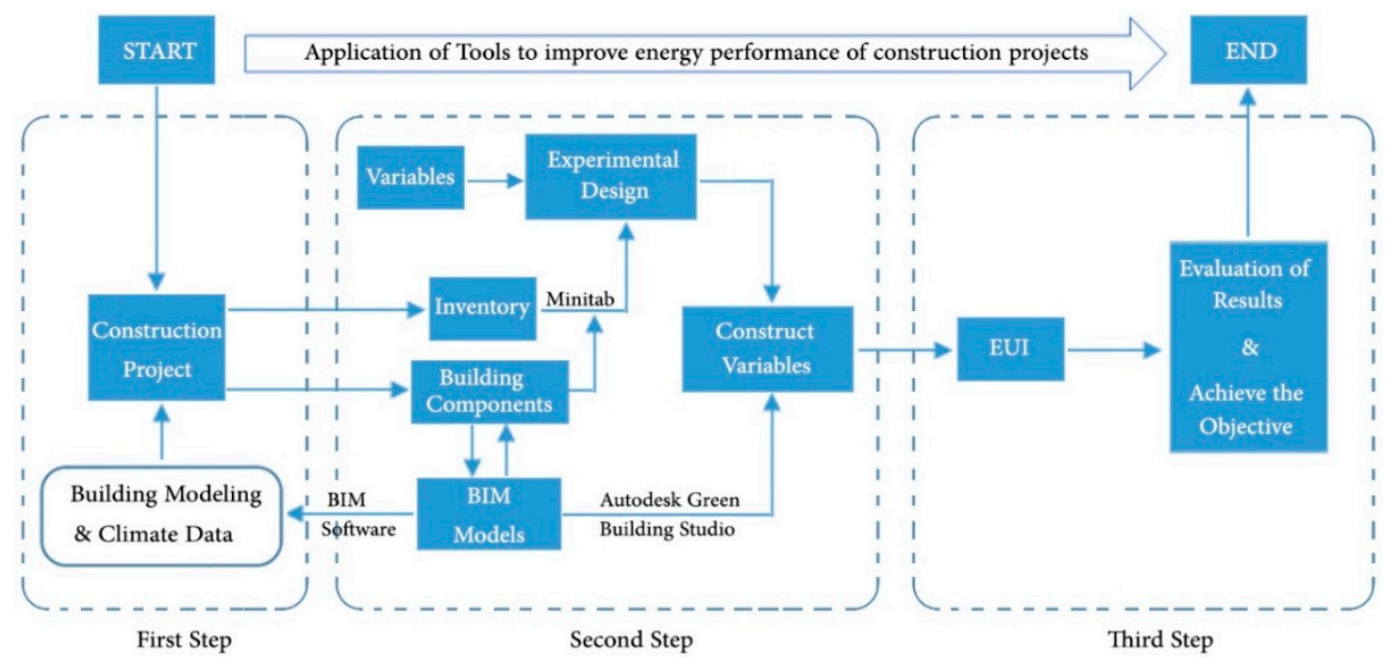

Figure 6. Linking framework components.

The proposed framework presented in Figure 5 and the linking component of this framework presented in Figure 6, can accommodate a large number of construction materials for exterior walls, roofs, window-to-wall ratio and any other component of the building envelop (i.e., windows, doors, floors and ceilings). However, the case study of this work will consider the exterior walls and roofs components and the window-to-wall ratio. This comes back to the fact that the exterior walls are responsible for the internal thermal comfort of occupants in buildings [75], while roofs are the part of buildings that receive the largest amount of solar radiation per square meter annually [76]. In addition to this, the window-to-wall ratio plays a basic role in heating loss and gain that could affect the thermal comfort of buildings [77]. The next section highlights the procedure in a case example. 


\section{Case Study: Validating the Methodological Framework in a Single-Family House}

The applied case study aims to validate the proposed framework, which is the novelty of this work, used to model the decisions involved in choosing the building components (i.e., exterior walls and roofs) and window-to-wall ratio for construction projects. In order to showcase the versatility of the proposed framework, the proposed analysis is conducted in six different cities with different climates, as shown in Table 1. The chosen cities include Dubai in United Arab of Emirates, Kuala Lumpur in Malaysia, Moscow in Russia, Mount Wellington in Australia, Porto in Portugal and Rio de Janeiro in Brazil. The choice of cities is made to ensure a comprehensive consideration of various climatic conditions. Rio de Janeiro and Kuala Lumpur belong to the Tropical Climates within different sub-type classifications, Tropical savanna climate and Tropical rainforest climate, respectively as shown in Table 1. The characterizations of Dubai, Moscow, Mount Wellington and Porto are Dry Climates, Continental Climates, Polar Climates and Mild Temperate Climates, respectively.

Table 1. Selected cities for this analysis [28-31,78].

\begin{tabular}{ccc}
\hline City & Climate Group & Sub-Type Classification \\
\hline Dubai & Dry Climates & Hot desert climate (BWh) \\
Kuala Lumpur & Tropical Climates & Tropical rainforest climate (Af) \\
Moscow & Continental Climates & Warm-summer humid continental climate (Dfb) \\
Mount Wellington & Polar Climates & Tundra climate (ET) \\
Porto & Mild Temperate Climates & Warm-summer Mediterranean climate (Csb) \\
Rio de Janeiro & Tropical Climates & Tropical savanna climate (Aw or As) \\
\hline
\end{tabular}

\subsection{Size of the Case Study}

The case study of this work examines the energy efficiency of a one-floor single-family house, consisting of three bedrooms, bathroom, kitchen and living room with a total floor area of $60 \mathrm{~m}^{2}$, using the basic appliances for heating and cooling (i.e., fan and heat pump), lighting (i.e., bulbs and plugs), equipment (refrigerator, cooker and washing machine) and hot water purposes (i.e., boiler. The plan layout of the house is shown in Figure 7. The selection of the case study is developed based on the ability to accommodate different construction materials that are assembling the building envelop. This could foster the simulation process of construction components and provide the basis for the application and extension of building materials. However, Autodesk Revit is used as a BIM software to build the modeling of the case study. This software enables the use of the model information database to perform different climate classifications of the examined cities presented in Table 1 and also to model the different alternative materials of the construction components that are assembling the building envelope.

The analysis takes into consideration two types of building materials for constructing the exterior walls and roof, namely Insulated Concrete Form (ICF) wall with 10-inch-thick form and ICF wall with a 14-inch-thick form for walls. Such types of walls are hollow foam blocks stacked into the shape of the exterior walls of a building, reinforced with steel rebar and filled with concrete. They combine one of the finest insulating materials such as expanded polystyrene, with one of the strongest structural building materials such as steel reinforced concrete, giving a wall system of unmatched comfort, energy efficiency, strength and noise reduction [79]. Continuous Deck Roof with Code Compliant Insulation and Continuous Deck Roof with Super High Insulation is considered for the roof; such types of roofs have a flat surface that is capable of supporting weight and providing noise and fire insulation [80]. The selection of two materials for each building component is for demonstration purposes; the proposed framework can accommodate a large number of construction materials for each building component, as previously discussed in Section 4 . Additionally, the parametric analysis considers a range of common window-to-wall ratios, including $15 \%, 30 \%, 40 \%, 50 \%$ and $65 \%$. 


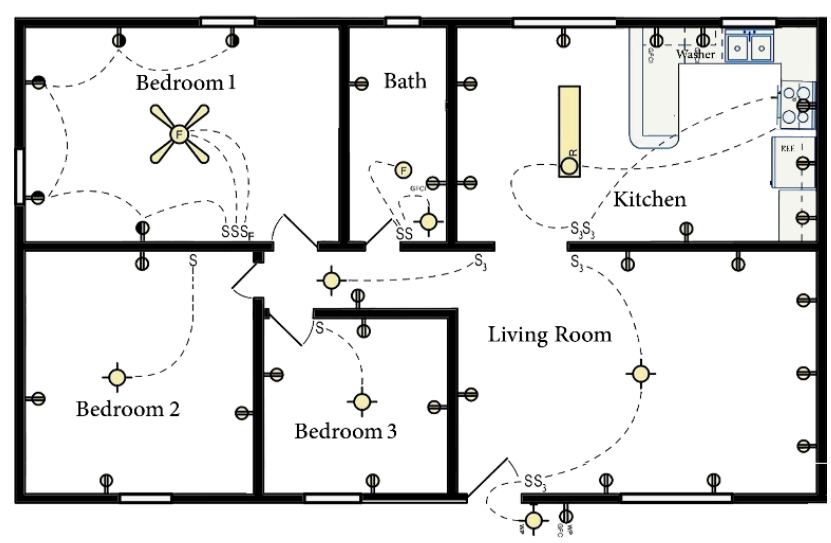

Figure 7. 2D plan of the single-family house.

\subsection{Inventory of Database}

The inventory of the database focusses on the operation phase of the building and is constructed through the three main steps highlighted in Section 4.

The first step is that the assigned design factors determined in the case study, Table 2, are integrated into a linear statistical regression, in order to cover all the expected variables of the experimental design. Application of the experimental design work outlined in the proposed framework is known as mixed-level design or general full factorial design, which allows the consideration of different levels for each factor [16]. In this study, three factors with different levels are incorporated: (i) the first factor is the wall type $\left(\mathrm{C}_{\mathrm{W}}\right)$, consisting of two levels, which considers two insulated concrete form walls; (ii) the second factor is the roof type $\left(C_{R}\right)$, consisting of two levels for the two types of continuous deck roof; (iii) the third factor is the window-to-wall ratio $\left(C_{W R}\right)$, which is associated with five levels considering various values of window-to-wall ratio, as displayed in Table 2. The selection of the construction components of the walls and roofs in the case study follows the necessity of increasing energy efficiency and insulation in construction projects as an introduction of advanced low energy cooling concept and a high efficiency heating concept [81].

Table 2. The applied alternatives of construction objects.

\begin{tabular}{llc}
\hline \multicolumn{1}{c}{ Wall $\left(\mathbf{C}_{\mathbf{W}}\right)$} & \multicolumn{1}{c}{ Roof $\left(\mathbf{C}_{\mathbf{R}}\right)$} & Window-to-Wall Ratio $\left(\mathbf{C}_{\mathbf{W R}}\right)$ \\
\hline Insulated Concrete Form (ICF) & Continuous Deck Roof with Code & $15 \%$ \\
wall, 10-inch-thick form. & Compliant Insulation. & $30 \%$ \\
Insulated Concrete Form (ICF) & Continuous Deck Roof with Super & $40 \%$ \\
wall, 14 inch thick form. & High Insulation. & $50 \%$ \\
& & $65 \%$ \\
\hline
\end{tabular}

The model for such an experimental analysis is presented in Equation (2). The number of sequences will be the result of multiplying together the number of levels associated with each factorial design considered within a single analysis $[16,82]$. As an example, the number of sequences that are required to cover all the expected variables in the case example examined is $20(2 \times 2 \times 5)$. The format of Equation (2) applied in the case study example of this work is as follows:

$$
E=\beta_{0}+\beta_{1} \cdot C_{W}+\beta_{2} \cdot C_{R}+\beta_{3} \cdot C_{W R}+\beta_{12} \cdot C_{W} \cdot C_{R}+\beta_{13} \cdot C_{W} \cdot C_{W R}+\beta_{23} \cdot C_{R} \cdot C_{W R}+\beta_{123} \cdot C_{W} \cdot C_{R} \cdot C_{W R}+\epsilon
$$

An interaction between the assigned factors that are defining the building is achieved to simulate all expected variables through the use of a statistical factorial design technique [66]. The energy analysis response (E) based on the main effects of $C_{W}, C_{R}$ and $C_{W R}$, as defined in Table 2, is captured in terms of $\left(C_{W} \cdot C_{R}\right),\left(C_{W} \cdot C_{W R}\right),\left(C_{R} \cdot C_{W R}\right)$ and $\left(C_{W} \cdot C_{R} \cdot C_{W R}\right)$; these terms are included to consider all possible interactions between the main variables. The constant $\beta_{0}$ is the response of energy analysis 
when all main effects are equal to zero, while $\beta_{1}, \beta_{2}, \beta_{3}, \beta_{12}, \beta_{13}, \beta_{23}$ and $\beta_{123}$ denote the unknown parameters to be estimated; the variable $\epsilon$ refers to the experimental error. Table 3 illustrates the experimental design analysis of the applied design factors.

The next step is to apply Autodesk Green Building Studio to estimate the EUI based on the running sequences that were previously built in the regression model of the experimental design. At this step, the database for each sequence is constructed individually. This means that a total of 20 separate analysis are performed in Autodesk Green Building Studio for each city. The third step involves the collection of the results in Autodesk Green Building Studio and integrating them into Minitab software, in order to evaluate the collected data and to estimate the main effects of the various design factors, based on the energy simulation in the chosen cities.

\subsection{Assessment of Design Factors}

The experimental design is applied at this level of the analysis to clarify the various effects of the assigned design factors. Figure 8 presents the estimated values of the EUI of the case study based on the examined cities in this work.

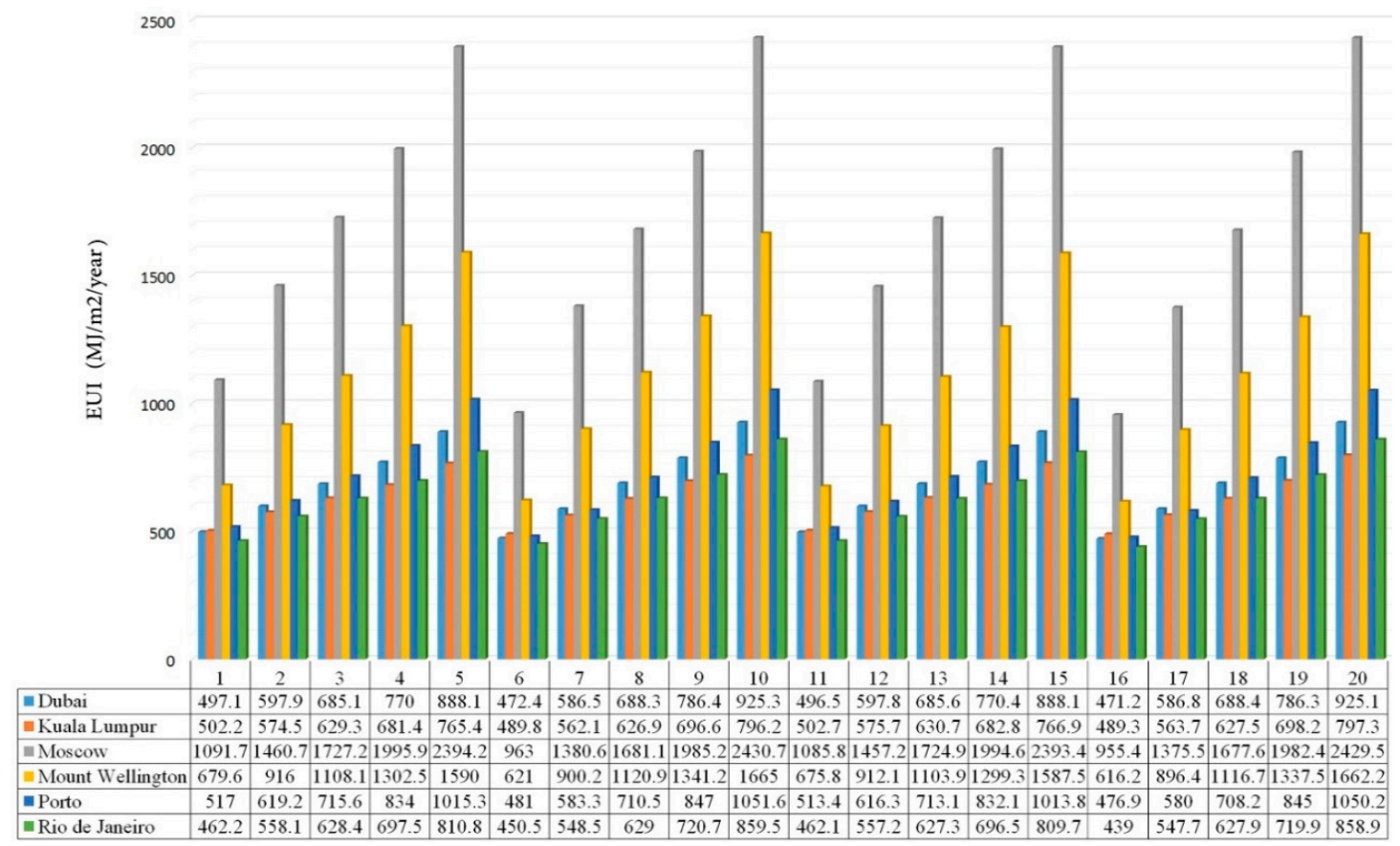

Figure 8. Energy Use Intensity (EUI) results of the case study.

The results of the regression equation, regression errors, coefficients, the main effects plot and interaction plot are fully presented within the supplementary file. The presented information in this file shows that there is no error (error $=0$ ) in conducting the analysis of variance in the six examined cities. The computation of EUI in Figure 8 is simulated individually in Autodesk Green Building Studio cloud-based service [83]. A total of 20 sequences are displayed for each city based on the factorial design analysis as presented in Table 3. 
Table 3. Experimental design outputs.

\begin{tabular}{ccccccc}
\hline \multirow{2}{*}{ Seq. } & \multicolumn{3}{c}{ Factorial Design } & & Wall & Roof \\
\cline { 2 - 4 } & $\mathbf{C}_{\mathbf{W}}$ & $\mathbf{C}_{\mathbf{R}}$ & $\mathbf{C}_{\mathbf{W R}}$ & & & Window-to-Wall Ratio \\
\hline 1 & 1 & 1 & 1 & ICF wall, 10 thick form & CDR with Code Compliant Insulation & $15 \%$ \\
2 & 1 & 1 & 2 & ICF wall, 10 thick form & CDR with Code Compliant Insulation & $30 \%$ \\
3 & 1 & 1 & 3 & ICF wall, 10 thick form & CDR with Code Compliant Insulation & $40 \%$ \\
4 & 1 & 1 & 4 & ICF wall, 10 thick form & CDR with Code Compliant Insulation & $50 \%$ \\
5 & 1 & 1 & 5 & ICF wall, 10 thick form & CDR with Code Compliant Insulation & $65 \%$ \\
6 & 1 & 2 & 1 & ICF wall, 10 thick form & CDR with Super High Insulation & $15 \%$ \\
7 & 1 & 2 & 2 & ICF wall, 10 thick form & CDR with Super High Insulation & $30 \%$ \\
8 & 1 & 2 & 3 & ICF wall, 10 thick form & CDR with Super High Insulation & $40 \%$ \\
9 & 1 & 2 & 4 & ICF wall, 10 thick form & CDR with Super High Insulation & $50 \%$ \\
10 & 1 & 2 & 5 & ICF wall, 10 thick form & CDR with Super High Insulation & $65 \%$ \\
11 & 2 & 1 & 1 & ICF wall, 14 thick form & CDR with Code Compliant Insulation & $15 \%$ \\
12 & 2 & 1 & 2 & ICF wall, 14 thick form & CDR with Code Compliant Insulation & $30 \%$ \\
13 & 2 & 1 & 3 & ICF wall, 14 thick form & CDR with Code Compliant Insulation & $40 \%$ \\
14 & 2 & 1 & 4 & ICF wall, 14 thick form & CDR with Code Compliant Insulation & $50 \%$ \\
15 & 2 & 1 & 5 & ICF wall, 14 thick form & CDR with Code Compliant Insulation & $65 \%$ \\
16 & 2 & 2 & 1 & ICF wall, 14 thick form & CDR with Super High Insulation & $15 \%$ \\
17 & 2 & 2 & 2 & ICF wall, 14 thick form & CDR with Super High Insulation & $30 \%$ \\
18 & 2 & 2 & 3 & ICF wall, 14 thick form & CDR with Super High Insulation & $40 \%$ \\
19 & 2 & 2 & 4 & ICF wall, 14 thick form & CDR with Super High Insulation & $50 \%$ \\
20 & 2 & 2 & 5 & ICF wall, 14 thick form & CDR with Super High Insulation & $65 \%$ \\
\hline
\end{tabular}

\subsection{Evaluation of Results}

At this level of the analysis, the plot and the interaction plot studies are conducted and analyzed in Minitab software based on the collected energy analysis results, in order to show the role of the assigned factorial designs for each city.

Analyzing the interaction plot of the factorial design for each city as presented in Figures S1-S6 in the supplementary file shows that the interaction of the factorial designs of the walls $\left(\mathrm{C}_{W}\right)$ and roofs $\left(C_{R}\right)$ has a slight influence on the energy consumption in the case study building. However, the interactions between these factors, individually and the window-to-wall ratio factor; $\left(C_{W}\right.$ and $\left.C_{W R}\right)$ and $\left(C_{R}\right.$ and $\left.C_{W R}\right)$ have the highest influence on improving energy efficiency in the case study building in the examined cities. Moreover, Figure 8 evaluates the energy efficiency of the construction project by highlighting the best building components that could affect the energy consumption in the case study. The results show that constructing buildings with minor openings (low window-to-wall ratio) using different building components for walls and roofs would consume less EUI than using wide opening spaces. In other words, using super high insulation building materials and increasing the thickness of building components that have a higher window-to-wall ratio, as seen in sequences 17, 18, 19 and 20, would slightly reduce the energy consumption in buildings. At the same time, sequence 16, which uses the same properties of materials as in the previous sequences with minor opening spaces, present a significant increase in energy efficiency in the cases examined. The results confirm that the space area of the exterior openings as a major building design aspect that influences the energy consumption of the building. This point is confirmed in Figures S7-S12 in the supplementary file by illustrating the main effects plot of the assigned design factors for each city, separately. Besides, Figure 8 illustrates that sequences 6 and 16 maximize the energy efficiency of the case study building in the six examined cities whereas sequences 5,10,15 and 20 would consume the most energy in all cities.

The analysis of the collected results presented in Figure 8 shows that there are several performance parameters to be considered in order to improve the energy efficiency in construction projects such as insulation and thickness of the building component, a space area of the exterior openings and climate data. For example, installing the case study with opening spaces of $15 \%$ in Rio de Janeiro (Tropical Climates) disregarding any other components of walls and roofs, as shown in sequences 1, 6 and 11 and in Dubai (Dry Climates) using super high insulation for roofs, as shown in sequences 6 and 16, would consume almost the same energy. While disregarding the insulation factor for roofs, as presented in sequences 1 and 11, would consume more energy in Dubai (within values of 497.1 and $496.5 \mathrm{MJ} / \mathrm{m}^{2} /$ year, respectively) than in Rio de Janeiro (within values of 462.2 and $462.1 \mathrm{MJ} / \mathrm{m}^{2} /$ year, respectively).

Adopting a window-to-wall ratio of $15 \%$ for the case study positioned in Mount Wellington (Polar Climates), as presented in sequences 6 and 16, would consume almost the same energy when 
adopting a window-to-wall ratio of 30\% in Dubai and Porto (Mild Temperate Climates), as presented in sequences 2, 7, 12 and 17. Besides, positioning the case study in Moscow (Continental Climates), sequences 6 and 16, would cause almost the same consumption in Dubai, sequences 10 and 20, with a window-to-wall ratio of $15 \%$ and $65 \%$, respectively. Adopting the case study with a window-to-wall ratio of $40 \%$ in Dubai and Porto, i.e., sequences 3, 8, 13 and 18, would consume the same energy in Kuala Lumpur and Rio de Janeiro i.e., sequences 4, 9, 14 and 19, with a window-to-wall ratio of 50\%, disregarding all other building components. Moreover, adopting the case study in Mount Wellington with a $40 \%$ opening space, disregarding any other components for walls and roofs, sequences $3,8,13$ and 18, would consume almost the same energy consumption compared to the same unit positioned in Moscow and adopted with a 15\% opening space, sequences 1 and 11 . Analyzing and comparing these results in Figure 8 with the obtained results in Figures S7-S12 in the supplementary file illustrate that colder weather equal to more energy consumption and vice versa. Figure 8 illustrates that the results of the EUI of the case study positioned in Kuala Lumpur and Rio de Janeiro are slightly different. This proves that the sub-type climate classification plays a minor role in determining energy efficiency whereas the climate group is the main agent of manipulating the energy consumption in such types of buildings.

Constructing the case study in Dubai with opening spaces of $50 \%$ and in Kuala Lumpur with opening spaces of $65 \%$, using CDR with Code Compliant Insulation, sequences 4 and 14 for Dubai and 5 and 15 for Kuala Lumpur and CDR with Super High Insulation for the roof, sequences 9 and 19 for Dubai and 10 and 20 for Kuala Lumpur and disregarding the thickness of the exterior walls, would result in almost the same consumption of EUI. This proves that the space area of the exterior openings is a major factor for improving energy efficiency in construction projects. This point is confirmed within the supplementary file; Figures S7-S12.

Analyzing the sequences of Figure 8; (1 to 5), (6 to 10), (11 to 15$)$ and (16 to 20), give the opportunity to estimate the proportional impact of the exterior openings on the EUI in the case study, considering similar construction components for walls and roofs in the examined cities. Table 4 illustrates an analysis of these groups of sequences based on adopting the case study within a gradual increase of the $\mathrm{C}_{\mathrm{RW}}$ between $15 \%, 30 \%, 40 \%, 50 \%$ and $65 \%$, disregarding the other components of walls and roofs. The proportional impact of the $C_{W R}$ on the EUI in the case study is then estimated by calculating the percentage increase of the EUI when adopting a building to sequential levels of the $C_{W R}$, as defined in Table 2, for each city, individually. Such analysis illustrates the correlation between the space area of the openings and EUI in the case study building.

Table 4. The proportional impact of the exterior openings on the EUI in the case study.

\begin{tabular}{|c|c|c|c|c|c|c|c|}
\hline Seq. & Gradual Increase of the $C_{W R}$ & Dubai & Kuala Lumpur & Moscow & Mount Wellington & Porto & Rio de Janeiro \\
\hline \multirow{4}{*}{1 to 5} & From $15 \%$ to $30 \%$ & $20.28 \%$ & $14.40 \%$ & $33.80 \%$ & $34.78 \%$ & $19.77 \%$ & $20.75 \%$ \\
\hline & From $30 \%$ to $40 \%$ & $14.58 \%$ & $9.54 \%$ & $18.24 \%$ & $20.97 \%$ & $15.57 \%$ & $12.60 \%$ \\
\hline & From $40 \%$ to $50 \%$ & $12.39 \%$ & $8.28 \%$ & $15.56 \%$ & $17.54 \%$ & $16.54 \%$ & $10.99 \%$ \\
\hline & From $50 \%$ to $65 \%$ & $15.34 \%$ & $12.33 \%$ & $19.95 \%$ & $22.07 \%$ & $21.74 \%$ & $16.24 \%$ \\
\hline \multirow{4}{*}{6 to 10} & From $15 \%$ to $30 \%$ & $24.15 \%$ & $14.76 \%$ & $43.36 \%$ & $44.96 \%$ & $21.27 \%$ & $21.75 \%$ \\
\hline & From $30 \%$ to $40 \%$ & $17.36 \%$ & $11.53 \%$ & $21.76 \%$ & $24.52 \%$ & $21.81 \%$ & $14.68 \%$ \\
\hline & From $40 \%$ to $50 \%$ & $14.25 \%$ & $11.12 \%$ & $18.09 \%$ & $19.65 \%$ & $19.21 \%$ & $14.58 \%$ \\
\hline & From $50 \%$ to $65 \%$ & $17.66 \%$ & $14.30 \%$ & $22.44 \%$ & $24.14 \%$ & $24.15 \%$ & $19.26 \%$ \\
\hline \multirow{4}{*}{11 to 15} & From $15 \%$ to $30 \%$ & $20.40 \%$ & $14.52 \%$ & $34.21 \%$ & $34.97 \%$ & $20.04 \%$ & $20.58 \%$ \\
\hline & From $30 \%$ to $40 \%$ & $14.69 \%$ & $9.55 \%$ & $18.37 \%$ & $21.03 \%$ & $15.71 \%$ & $12.58 \%$ \\
\hline & From $40 \%$ to $50 \%$ & $12.37 \%$ & $8.26 \%$ & $15.63 \%$ & $17.70 \%$ & $16.69 \%$ & $11.03 \%$ \\
\hline & From $50 \%$ to $65 \%$ & $15.28 \%$ & $12.32 \%$ & $19.99 \%$ & $22.18 \%$ & $21.84 \%$ & $16.25 \%$ \\
\hline \multirow{4}{*}{16 to 20} & From $15 \%$ to $30 \%$ & $24.53 \%$ & $15.20 \%$ & $43.97 \%$ & $45.47 \%$ & $21.62 \%$ & $24.76 \%$ \\
\hline & From $30 \%$ to $40 \%$ & $17.31 \%$ & $11.32 \%$ & $21.96 \%$ & $24.57 \%$ & $22.10 \%$ & $14.64 \%$ \\
\hline & From $40 \%$ to $50 \%$ & $14.22 \%$ & $11.27 \%$ & $18.17 \%$ & $19.77 \%$ & $19.32 \%$ & $14.65 \%$ \\
\hline & From $50 \%$ to $65 \%$ & $17.65 \%$ & $14.19 \%$ & $22.55 \%$ & $24.28 \%$ & $24.28 \%$ & $19.31 \%$ \\
\hline
\end{tabular}

The results collected in Table 4 present the following:

1. Adopting a building where the $\mathrm{C}_{\mathrm{RW}}$ is $30 \%$ instead of $15 \%$, would influence the EUI in the case study by a percentage between $20.28 \%$ and $24.53 \%$ in Dubai; $14.40 \%$ and $15.20 \%$ in Kuala Lumpur; 
$33.80 \%$ and $43.97 \%$ in Moscow; $34.78 \%$ and $45.47 \%$ in Mount Wellington; $19.77 \%$ and $21.62 \%$ in Porto; and $20.58 \%$ and $24.76 \%$ in Rio de Janeiro.

2. Adopting a building where the $\mathrm{C}_{\mathrm{RW}}$ is $40 \%$ instead of $30 \%$, would influence the EUI in the case study by a percentage between $14.58 \%$ and $17.36 \%$ in Dubai; $9.54 \%$ and $11.53 \%$ in Kuala Lumpur; $18.24 \%$ and $21.96 \%$ in Moscow; 20.97\% and 24.57\% in Mount Wellington; $15.57 \%$ and $22.10 \%$ in Porto; and $12.58 \%$ and $14.68 \%$ in Rio de Janeiro.

3. Adopting a building where the $\mathrm{C}_{\mathrm{RW}}$ is $50 \%$ instead of $40 \%$, would influence the EUI in the case study by a percentage between $12.37 \%$ and $14.25 \%$ in Dubai; $8.26 \%$ and $11.27 \%$ in Kuala Lumpur; $15.56 \%$ and $18.17 \%$ in Moscow; $17.54 \%$ and $19.77 \%$ in Mount Wellington; $16.54 \%$ and $19.32 \%$ in Porto; and $10.99 \%$ and $14.65 \%$ in Rio de Janeiro.

4. Adopting a building where the $\mathrm{C}_{\mathrm{RW}}$ is $65 \%$ instead of $50 \%$, would influence the EUI in the case study by a percentage between $15.28 \%$ and $17.66 \%$ in Dubai; $12.32 \%$ and $14.30 \%$ in Kuala Lumpur; $19.95 \%$ and $22.55 \%$ in Moscow; $22.07 \%$ and $24.28 \%$ in Mount Wellington; $21.74 \%$ and $24.28 \%$ in Porto; and $16.24 \%$ and $19.31 \%$ in Rio de Janeiro.

Furthermore, this work conducts another analysis to estimate the proportional impact of the construction components of exterior walls and roofs on the EUI in the case study, considering similar $C_{W R}$ factors. This requires organizing the sequences of Figure 8 in groups as follows: $C_{W R}$ of $15 \%(1,6$, 11 and 16$), C_{W R}$ of $30 \%(2,7,12$ and 17$), C_{W R}$ of $40 \%(3,8,13$ and 18$), C_{W R}$ of $50 \%(4,9,14$ and 19) and $C_{W R}$ of $65 \%(5,10,15$ and 20). Then, the proportional impact of the construction components of exterior walls and roofs is calculated based on the lowest and highest EUI values for each group, as shown in Table 5.

Table 5. The proportional impact of the construction components of walls and roofs on the EUI in the case study based on window-to-wall ratio.

\begin{tabular}{|c|c|c|c|c|c|c|c|}
\hline $\mathrm{C}_{\mathrm{WR}}$ & EUI (MJ/m²/year) & Dubai & Kuala Lumpur & Moscow & Mount Wellington & Porto & Rio de Janeiro \\
\hline \multirow{2}{*}{$15 \%$} & Lowest & 471.2 & 489.3 & 955.4 & 616.2 & 476.9 & 439 \\
\hline & Highest & 497.1 & 502.7 & 1091.7 & 679.6 & 517 & 462.2 \\
\hline \multicolumn{2}{|c|}{ Proportional Impact } & $5.50 \%$ & $2.74 \%$ & $14.27 \%$ & $10.29 \%$ & $8.41 \%$ & $5.28 \%$ \\
\hline \multirow{2}{*}{$30 \%$} & Lowest & 586.5 & 562.1 & 1375.5 & 896.4 & 580 & 547.7 \\
\hline & Highest & 597.9 & 575.7 & 1460.7 & 916 & 619.2 & 558.1 \\
\hline \multicolumn{2}{|c|}{ Proportional Impact } & $1.94 \%$ & $2.42 \%$ & $6.19 \%$ & $2.19 \%$ & $6.76 \%$ & $1.90 \%$ \\
\hline \multirow{2}{*}{$40 \%$} & Lowest & 685.1 & 626.9 & 1677.6 & 1103.9 & 708.2 & 627.3 \\
\hline & Highest & 688.4 & 630.7 & 1727.2 & 1120.9 & 715.6 & 629 \\
\hline \multicolumn{2}{|c|}{ Proportional Impact } & $0.48 \%$ & $0.61 \%$ & $2.97 \%$ & $1.54 \%$ & $1.04 \%$ & $0.27 \%$ \\
\hline \multirow{2}{*}{$50 \%$} & Lowest & 770 & 681.4 & 1982.4 & 1299.3 & 832.1 & 696.5 \\
\hline & Highest & 786.4 & 698.2 & 1995.9 & 1341.2 & 847 & 720.7 \\
\hline \multicolumn{2}{|c|}{ Proportional Impact } & $2.12 \%$ & $2.47 \%$ & $0.68 \%$ & $3.23 \%$ & $1.79 \%$ & $3.47 \%$ \\
\hline \multirow{2}{*}{$65 \%$} & Lowest & 888.1 & 765.4 & 2393.4 & 1587.5 & 1013.8 & 809.7 \\
\hline & Highest & 925.3 & 797.3 & 2430.7 & 1665 & 1051.6 & 859.5 \\
\hline \multicolumn{2}{|c|}{ Proportional Impact } & $4.19 \%$ & $4.17 \%$ & $1.56 \%$ & $4.88 \%$ & $3.73 \%$ & $6.15 \%$ \\
\hline
\end{tabular}

The results presented in Table 5 illustrate that the proportional impacts of the construction components of exterior walls and roofs in the case study would vary as follows:

(a) $5.50 \%$ in Dubai, $2.74 \%$ in Kuala Lumpur, $14.27 \%$ in Moscow, $10.29 \%$ in Mount Wellington, $8.41 \%$ in Porto and $5.28 \%$ in Rio de Janeiro, considering a $\mathrm{C}_{\mathrm{WR}}$ of $15 \%$.

(b) $1.94 \%$ in Dubai, $2.42 \%$ in Kuala Lumpur, $6.19 \%$ in Moscow, $2.19 \%$ in Mount Wellington, $6.76 \%$ in Porto and $1.90 \%$ in Rio de Janeiro, considering a $\mathrm{C}_{\mathrm{WR}}$ of $30 \%$.

(c) $0.48 \%$ in Dubai, $0.61 \%$ in Kuala Lumpur, $2.97 \%$ in Moscow, $1.54 \%$ in Mount Wellington, $1.04 \%$ in Porto and $0.27 \%$ in Rio de Janeiro, considering a $C_{W R}$ of $40 \%$.

(d) $2.12 \%$ in Dubai, $2.47 \%$ in Kuala Lumpur, $0.68 \%$ in Moscow, $3.23 \%$ in Mount Wellington, $1.79 \%$ in Porto and $3.47 \%$ in Rio de Janeiro, considering a $\mathrm{C}_{\mathrm{WR}}$ of $50 \%$.

(e) $4.19 \%$ in Dubai, $4.17 \%$ in Kuala Lumpur, $1.56 \%$ in Moscow, $4.88 \%$ in Mount Wellington, $3.73 \%$ in Porto and $6.15 \%$ in Rio de Janeiro, considering a $C_{W R}$ of $65 \%$. 


\section{Insights}

This study examines several building components of the exterior parts of buildings, along with different window-to-wall ratios in order to improve energy efficiency in buildings. The roles of the selected factorial designs for each city were evaluated in Minitab software based on the collected energy plot. The analysis revealed that climate data has a fundamental role in determining the energy consumption in buildings; the output results show that the energy consumption of the same building varies based on the climate data of the construction site, however, colder weather equal to more energy consumption and vice versa. For example, there would be a loss of $33-50 \%$ in energy levels when constructing the same building in continental climates and in polar climates, respectively, compared to other climate classifications such as dry climates, tropical climates and mild temperate climates. However, the results of the case study proved that the sub-type climate classifications have a minor role in influencing energy consumption in buildings. The collected results show that the building components of the exterior walls and roofs have an impact on the energy efficiency in buildings, however, the space area of openings remains a significant factor among the other building components that are highly influencing the consumption of energy in construction projects (see supplementary file). The conducted analysis of this work shows a strong relation between the openings and the EUI. In these terms, comparing the collected results in Tables 4 and 5, it can be recognized that the construction component of the walls and roof would play a minor role in influencing the energy consumption in buildings, compared to the significant role of the exterior openings in buildings. This point was confirmed in the interaction plot of the factorial design for each city as presented in the supplementary file. For example, the minimum proportional impact of the exterior openings on the EUI when adopting the case study within a gradual increase of window-to-wall ratio from $15 \%$ to $30 \%$ is $20.28 \%, 14.40 \%, 33.80 \%, 34.78 \%, 19.77 \%$ and $20.58 \%$, in Dubai, Kuala Lumpur, Moscow, Mount Wellington, Porto and Rio de Janeiro, respectively. While, the proportional impact of the construction components of the exterior walls and roofs is $5.50 \%$ and $1.94 \%$ in Dubai, $2.74 \%$ and $2.42 \%$ in Kuala Lumpur, $14.27 \%$ and $6.19 \%$ in Moscow, $10.29 \%$ and $2.19 \%$ in Mount Wellington, $8.41 \%$ and $6.76 \%$ in Porto, $5.28 \%$ and $1.90 \%$ in Rio de Janeiro, when adopting the case study within a window-to-wall ratio of $15 \%$ and $30 \%$, respectively. Hence, it is clear that considering the space area of exterior doors and windows at the required percentage and choosing the proper insulation and thickness of construction materials that are assembling the components of walls and roof would generate better results in terms of EUI, for all climate classifications and would improve the energy performance buildings, leading to lower-energy buildings.

The analysis of the collected results of this work indicates that there is a growing interest in using BIM to improve energy efficiency in buildings. It is considered an ideal procedure for empowering the sustainability and decision-making process in the construction sector $[2,8]$. The proposed framework can be easily expanded to accommodate a large number of building materials for exterior walls, roofs, window-to-wall ratio or any other component of the building envelop. The proposed framework is designed to be readily available to practitioners in the construction sector, via the use of standard procedure and software in their projects, to empower the decision-making process and sustainability of building projects through a parametric analysis of construction components. This provides an opportunity to analyze and examine several construction materials that are assembling any building components in a way to improve energy efficiency in their designs.

This work focused on exterior walls as a major component of a building that is responsible for internal thermal comfort of occupants [75], roofs as an important component of a building that receives the largest amount of solar radiation per square meter annually $[76,84]$ and window-to-wall ratio as basic factor that could affect the thermal comfort of buildings [77]. Hence, achieving the energy efficiency of such components and ratio could aid sustainability within the built environment. BIM approach has the ability to produce adjustable smart objects and easy to modify and allow using different building components within various design parameters in order to estimate the energy performance of buildings $[15,72,85]$. In these terms, the experimental design appears as an optimistic 
course that facilitates determining the expected variables of the construction process in light of the accessible construction materials [64].

\section{Conclusions}

Energy performance in buildings is important to consider in order to enhance the sustainability of the built environment. In an attempt to design better energy performing buildings, the work in this study presented a methodological framework that could help to integrate the experimental design within a BIM platform in order to examine all the possible design variables that impact the energy levels of buildings. The novelty of this work is to propose a framework that makes use of different performance parameters and design factors for a parametric sustainability evaluation process of building designs. The emphasis of the developed framework is on the energy performance of buildings through making the work readily available to practitioners and experts in the construction sector using standard procedure and software. The analysis considers the materials of building components, window-to-wall ratios and the energy consumed for heating, cooling, lighting and equipment purposes. The integrated methodological framework presented was based on the experimental design for determining the impact of various performance parameters related to several design factors, improving energy efficiency based on a parametric analysis. Autodesk Revit is used as a BIM software to build the building modeling; defining the building components and climate data. Minitab was utilized as an experimental tool to conduct linear regression analysis covering all the expected variables and to define the main effects plot and the interaction plot of the assigned design factors. Autodesk Green Building Studio cloud-based service was adopted as a BIM tool to analyze and estimate energy consumption.

A case study of a single-family house with different alternatives for construction components was examined in six cities, each with a different climate classification. Cities analyzed included Dubai, Kuala Lumpur, Moscow, Mount Wellington, Port and Rio de Janeiro. The results of this work indicated that the performance parameters suggested in the proposed framework significantly influence the consumption of energy in buildings. These parameters include the type of building design (i.e., the design of the final roof and exterior walls) and the climate data. In particular, the results displayed that applying super high insulation building components would slightly impact the energy efficiency in construction projects, while the design factor of the window-to-wall ratio plays a major role in influencing the energy consumption towards low-energy buildings. This work suggests constructing buildings with minor opening spaces in order to improve energy efficiency. The sub-type climate classifications have a minor role in influencing the energy consumption in buildings, while the climate group plays a fundamental role in determining this fact in construction projects. This idea was proved by showing that the same building consumed high energy when it was constructed in continental climates and polar climates whereas this value reduced dramatically in other climate classifications such as dry climates, tropical climates and mild temperate climates. In other words, it can be recognized that more windows equal to less energy efficiency and colder weather equal to more energy consumption.

The limitations of this work can be stated as follows. First, the case example of this work examined the construction of a single-family house, without considering the impact of building classification on energy consumption (i.e., office buildings, industrial buildings and mixed-use buildings). The second limitation lies in selecting a limited range of building materials, mostly materials that are available on the dataset of the Autodesk Green Building Studio cloud-based service. The framework can, however, be easily expanded to cover additional materials subject to the availablity of sufficient data. The authors' future research avenues will focus on examining other types of buildings, considering various sub-type classifications in order to point out reliable results.

Supplementary Materials: The following are available online at http://www.mdpi.com/1996-1073/12/8/1515/s1, Figure S1: Interaction Plot for Dubai, Figure S2: Interaction Plot for Kuala Lumpur, Figure S3: Interaction Plot for Moscow, Figure S4: Interaction Plot for Mount Wellington, Figure S5: Interaction Plot for Porto, Figure S6: Interaction Plot for Rio de Janeiro, Figure S7: Main Effects Plot for Dubai, Figure S8: Main Effects Plot for Kuala Lumpur, Figure S9: Main Effects Plot for Moscow, Figure S10: Main Effects Plot for Mount Wellington, Figure S11: Main Effects Plot for Porto, Figure S12: Main Effects Plot for Rio de Janeiro. 
Author Contributions: Data curation, A.W.A.H.; Formal analysis, V.W.Y.T.; Funding acquisition, A.H.; Methodology, M.K.N. and A.W.A.H.; Resources, M.K.N.; Software, M.K.N.; Supervision, A.H.; Validation, L.T.D.G., A.C.J.E. and A.H.; Writing-Original draft, M.K.N.

Funding: This research was funded by CNPq (Brazilian National Council for Scientific and Technological Development) grant number [307084/2015-9], and the APC was funded by Departamento de Construção Civil/UFRJ.

Acknowledgments: The authors want to acknowledge the financial support from CAPES Foundation (Coordination for the Improvement of Higher Education Personnel)—Finance Code 001.

Conflicts of Interest: The authors declare no conflicts of interest.

\section{References}

1. Lasvaux, S. Study of a Simplified Model for the Life Cycle Analysis of Buildings; Paris Institute de Technologie: Paris, France, 2010.

2. Wong, J.K.W.; Zhou, J. Enhancing environmental sustainability over building life cycles through green BIM: A review. Autom. Constr. 2015, 57, 156-165. [CrossRef]

3. Li, Y.; Zhu, N.; Qin, B. What Affects the Progress and Transformation of New Residential Building Energy Efficiency Promotion in China: Stakeholders' Perceptions. Energies 2019, 12, 1027. [CrossRef]

4. Ballarini, I.; De Luca, G.; Paragamyan, A.; Pellegrino, A.; Corrado, V. Transformation of an Office Building into a Nearly Zero Energy Building (nZEB): Implications for Thermal and Visual Comfort and Energy Performance. Energies 2019, 12, 895. [CrossRef]

5. Lechner, N. Heating, Cooling, Lighting: Sustainable Design Methods for Architects; John Wiley \& Sons: Hoboken, NJ, USA, 2014. Available online: https://books.google.com.br/books?hl=pt-BR\&lr=\&id=WjetCwAAQBAJ\& $\mathrm{oi}=$ fnd\&pg $=$ PR11\&dq=Heating,+ Cooling,+ Lighting + Sustainable+Design + Methods + for + Architects + 4th\&ots=YNKgETPI88\&sig=6LA9wCMFfTyJm6opj9g6hpCHjFQ\#v=onepage\&q=Heating\%2CCooling\% 2C (accessed on 16 April 2019).

6. Lundström, L.; Akander, J.; Zambrano, J. Development of a Space Heating Model Suitable for the Automated Model Generation of Existing Multifamily Buildings-A Case Study in Nordic Climate. Energies 2019, $12,485$. [CrossRef]

7. Kim, S.; Song, Y.; Sung, Y.; Seo, D.; Sung, Y. Development of a Consecutive Occupancy Estimation Framework for Improving the Energy Demand Prediction Performance of Building Energy Modeling Tools. Energies 2019, 12, 433. [CrossRef]

8. Najjar, M.; Figueiredo, K.; Palumbo, M.; Haddad, A. Integration of BIM and LCA: Evaluating the environmental impacts of building materials at an early stage of designing a typical office building. J. Build. Eng. 2017, 14, 115-126. [CrossRef]

9. Anand, C.K.; Amor, B. Recent developments, future challenges and new research directions in LCA of buildings: A critical review. Renew. Sustain. Energy Rev. 2017, 67, 408-416. [CrossRef]

10. UNEP. Buildings and Climate Change: Status, Challenges and Opportunities; UNEP: Nairobi, Kenya, 2007.

11. Jrade, A.; Jalaei, F. Integrating building information modeling (BIM) and energy analysis tools with green building certification system to conceptually design sustainable buildings. J. Inf. Technol. Constr. 2014, 19, 494-519.

12. Petri, I.; Kubicki, S.; Rezgui, Y.; Guerriero, A.; Li, H. Optimizing energy efficiency in operating built environment assets through building information modeling: A case study. Energies 2017, 10, 1167. [CrossRef]

13. Autodesk. Building Information Modelling for Sustainable Design: Conceptual Building Performance Analysis Overview. 2011. Available online: http://www.sustainabilityworkshop.autodesk.com (accessed on 23 December 2018).

14. GhaffarianHosein, A.; Zhang, T.; Nwadigo, O.; GhaffarianHosein, A.; Naismith, N.; Tookey, J.; Raahemifar, K. Application of nD BIM Integrated Knowledge-based Building Management System (BIM-IKBMS) for inspecting post-construction energy effieciency. Renew. Sustain. Energy Rev. 2017, 72, 935-949. [CrossRef]

15. Succar, B. Automation in Construction Building information modelling framework: A research and delivery foundation for industry stakeholders. Autom. Constr. 2009, 18, 357-375. [CrossRef]

16. Nist Sematech. Process Improvement. In: Engineering Statistics. 2012. Available online: http://www.itl.nist. gov/div898/handbook/pri/pri.htm (accessed on 28 May 2018). 
17. Eastman, C.; Teicholz, P.; Sacks, R.; Liston, K. BIM Handbook: A Guide to Building Information Modeling for Owners, Managers, Designers, Engineers and Contractors, 2nd ed.; Wiley: Hoboken, NJ, USA, 2011; 648p.

18. Autodesk. Building Information Modeling for Sustainable Design; U.S. Department of Energy, Energy Efficiency and Renewable Energy Network (EREN), Center of Excellence for Sustainable Development: Washington, DC, USA, 2003.

19. Bomfim, C.A.A.; Lisboa, B.T.W.; de Matos, P.C.C. Gestão de Obras com BIM-Uma nova era para o setor da Construção Civil Construction Management with BIM-A new era for the Construction sector Metodologia. In Proceedings of the SIGraDi 2016, XX Congress of the Iberoamerican Society of Digital Graphics, Buenos Aires, Argentina, 9-11 November 2016; pp. 556-560.

20. Jupp, J. 4D BIM for Environmental Planning and Management. Procedia Eng. 2017, 180, 190-201. [CrossRef]

21. Lu, Q.; Won, J.; Cheng, J.C.P. A financial decision making framework for construction projects based on 5D Building Information Modeling (BIM). Int. J. Proj. Manag. 2016, 34, 3-21. [CrossRef]

22. Barrett, P.; Baldry, D. Facilities Management: Towards Best Practice, 2nd ed. 2003. Available online: https://www.amazon.com/Facilities-Management-Towards-Best-Practice/dp/0632064455 (accessed on 16 April 2019).

23. Smith, P. BIM \& the 5D Project Cost Manager. Procedia Soc. Behav. Sci. 2014, 119, 475-484.

24. Fadeyi, M.O. Gulf Organisation for Research and Development The role of building information modeling (BIM) in delivering the sustainable building value. Int. J. Sustain. Built Environ. 2017, 6, 711-722. [CrossRef]

25. Zhai, Z.J.; Helman, J.M. Implications of climate changes to building energy and design. Sustain. Cities Soc. 2019, 44, 511-519. [CrossRef]

26. Waddicor, D.A.; Fuentes, E.; Sisó, L.; Salom, J.; Favre, B.; Jiménez, C.; Azar, M. Climate change and building ageing impact on building energy performance and mitigation measures application: A case study in Turin, northern Italy. Build. Environ. 2016, 102, 13-25. [CrossRef]

27. Chmielewski, F.-M.; Blümel, K.; Henniges, Y.; Blanke, M.; Weber, R.W.; Zoth, M. Phenological models for the beginning of apple blossom in Germany. Meteorol. Z. 2011, 20, 487-496. [CrossRef]

28. Chen, D.; Chen, H.W. Using the Köppen classification to quantify climate variation and change: An example for 1901-2010. Environ. Dev. 2013, 6, 69-79. [CrossRef]

29. Arnfield, A.J. Köppen Climate Classification. Encyclopaedia Britannica. 2017. Available online: https: //www.britannica.com/science/Koppen-climate-classification (accessed on 25 February 2019).

30. Rubel, F.; Kottek, M. Observed and projected climate shifts 1901-2100 depicted by world maps of the Koppen-Geiger climate classifcation World Map of Köppen-Geiger Climate Classification. Meteorol. Z. 2010, 19, 135-141. [CrossRef]

31. Yoo, J.; Rohli, R.V. Global distribution of Köppen-Geiger climate types during the Last Glacial Maximum, Mid-Holocene and present. Palaeogeogr. Palaeoclimatol. Palaeoecol. 2016, 446, 326-337. [CrossRef]

32. Rahman, H.; Han, H. Correlation of Ventilative Cooling Potentials and Building Energy Savings in Various Climatic Zones. Energies 2019, 12, 968. [CrossRef]

33. Azhar, S.; Brown, J. BIM for Sustainability Analyses. Int. J. Constr. Educ. Res. 2009, 5, 276-292. [CrossRef]

34. Jeong, W.; Son, J. An Algorithm to Translate Building Topology in Building Information Modeling into Object-Oriented Physical Modeling-Based Building Energy Modeling. Energies 2016, 9, 50. [CrossRef]

35. Brown, J.W.; Sattineni, A.; Azhar, S. A Case Study of Building Performance Analyses Using Building Information Modeling. In Proceedings of the 27th International Symposium on Automation and Robotics in Construction, Bratislava, Slovakia, 25-27 June 2010; pp. 213-222.

36. Chong, H.-Y.; Lee, C.-Y.; Wang, X. A mixed review of the adoption of Building Information Modelling (BIM) for sustainability. J. Clean. Prod. 2017, 142, 4114-4126. [CrossRef]

37. Ilhan, B.; Yaman, H. Automation in Construction Green building assessment tool (GBAT) for integrated BIM-based design decisions. Autom. Constr. 2016, 70, 26-37. [CrossRef]

38. Azhar, S.; Nadeem, A.; Mok, J.Y.N.; Leung, B.H.Y. Building Information Modeling (BIM): A New Paradigm for Visual Interactive Modeling and Simulation for Construction Projects. In Proceedings of the First International Conference on Construction in Developing Countries (ICCIDC-I), Karachi, Pakistan, 4-5 August 2008; pp. 435-446.

39. European Commission. Good Practice in Energy Efficiency: For a Sustainable, Safer and More Competitive Europe. 2015. Available online: https://ec.europa.eu/energy/sites/ener/files/documents/good_practice_in_ee_ -web.pdf (accessed on 16 April 2019). 
40. Halverson, M.A.; Athalye, R.A.; Rosenberg, M.I.; Hart, P.R.; Richman, E.E.; Winiarski, D.W. ANSI/ASHRAE/IES Standard 90.1-2013 Determination of Energy Savings: Quantitative Analysis; Pacific Northwest National Lab. (PNNL): Richland, WA, USA, 2014.

41. Khoshbakht, M.; Gou, Z.; Dupre, K. Energy use characteristics and benchmarking for higher education buildings. Energy Build. 2018, 164, 61-76. [CrossRef]

42. Huo, T.; Cai, W.; Ren, H.; Feng, W.; Zhu, M.; Lang, N.; Gao, J. China's building stock estimation and energy intensity analysis. J. Clean. Prod. 2019, 207, 801-813. Available online: https://linkinghub.elsevier.com/ retrieve/pii/S0959652618330749. [CrossRef]

43. Choi, J.-H. Investigation of the correlation of building energy use intensity estimated by six building performance simulation tools. Energy Build. 2017, 147, 14-26. [CrossRef]

44. Valentin EnergieSoftware GmbH. Design and Simulation of Photovoltaic Systems; Valentin EnergieSoftware GmbH: Berlin, Germany, 2010.

45. Almeida, H.S. Thermal Comfort Analysis of Buildings Using Theoretical and Adaptive Models; Universidade Técnica de Lisboa: Lisbon, Portugal, 2010.

46. Scuderi, G. Designing Flexibility and Adaptability: The Answer to Integrated Residential Building Retrofit. Designs 2019, 3, 3. [CrossRef]

47. Akadiri, P.O.; Chinyio, E.A.; Olomolaiye, P.O. Design of A Sustainable Building: A Conceptual Framework for Implementing Sustainability in the Building Sector. Buildings 2012, 2, 126-152. [CrossRef]

48. Bueno, C.; Fabricio, M.M. Comparative analysis between a complete LCA study and results from a BIM-LCA plug-in. Autom. Constr. 2018, 90, 188-200. [CrossRef]

49. Yin, B.C.L.; Laing, R.; Leon, M.; Mabon, L. An evaluation of sustainable construction perceptions and practices in Singapore. Sustain. Cities Soc. 2018, 39, 613-620. [CrossRef]

50. Sharma, M. Development of a 'Green building sustainability model' for Green buildings in India. J. Clean. Prod. 2018, 190, 538-551. [CrossRef]

51. Kissi, E.; Sadick, M.; Agyemang, D.Y. Drivers militating against the pricing of sustainable construction materials: The Ghanaian quantity surveyors perspective. Case Stud. Constr. Mater. 2018, 8, 507-516. [CrossRef]

52. Zangheri, P.; Armani, R.; Pietrobon, M.; Pagliano, L.; Fernandez Boneta, M.; Müller, A. Heating and Cooling Energy Demand and Loads for Building Types in Different Countries of the EU. 2014. Available online: http://www.entranze.eu/files/downloads/D2_3/Heating_and_cooling_energy_demand_and_loads_ for_building_types_in_different_countries_of_the_EU.pdf (accessed on 16 April 2019).

53. Federal Office for Building and Regional Planing. Guideline for Sustainable Building; Federal Office for Building and Regional Planing: Berlin, Germany, 2001.

54. De Boer, R.C.; van Vliet, H. On the similarity between requirements and architecture. J. Syst. Softw. 2009, 82, 544-550. [CrossRef]

55. Brkljač, D.; Milinković, A.; Hiel, K.; Đerić, J. Role of building morphology in establishing of the urban context. In: 41th Anniversary Faculty of Civil Engineering Subotica. 2015, pp. 807-814. Available online: www.gf.uns.ac.rs/ \{\}zbornik/doc/NS2015.086.pdf (accessed on 16 April 2019).

56. ANSI/ASHRAE Standard. Thermal Environment Conditions for Human Occupacy; ASHRAE: Atlanta, GA, USA, 2013.

57. Autodesk. Software de Modelagem de Informações de Construção. Revit Recursos. Available online: https://www.autodesk.com.br/products/revit/features (accessed on 30 March 2019).

58. Jalaei, F. Integrate Building Information Modeling (Bim) and Sustainable Design at the Conceptual Stage of Building Projects. Ph.D. Thesis, University of Ottawa, Ottawa, ON, Canada, 2015.

59. Natephra, W.; Yabuki, N.; Fukuda, T. Optimizing the evaluation of building envelope design for thermal performance using a BIM-based overall thermal transfer value calculation. Build. Environ. 2018, 136, 128-145. [CrossRef]

60. Gokarakonda, S.; Van Treeck, C.; Rawal, R. Influence of building design and control parameters on the potential of mixed-mode buildings in India. Build. Environ. 2019, 148, 157-172. [CrossRef]

61. Benestad, R.; Parding, K.; Dobler, A.; Mezghani, A. A strategy to effectively make use of large volumes of climate data for climate change adaptation. Clim. Serv. 2017, 6, 48-54. [CrossRef]

62. Chilkoti, V.; Bolisetti, T.; Balachandar, R. Climate change impact assessment on hydropower generation using multi-model climate ensemble. Renew. Energy 2017, 109, 510-517. [CrossRef] 
63. Žigart, M.; Kovačič Lukman, R.; Premrov, M.; Žegarac Leskovar, V. Environmental impact assessment of building envelope components for low-rise buildings. Energy 2018, 163, 501-512. [CrossRef]

64. Callao, M.P. Trends in Analytical Chemistry Multivariate experimental design in environmental analysis. Trends Anal. Chem. 2014, 62, 86-92. [CrossRef]

65. Autodesk. Weather Data Sources and Methodology. Autodesk Knowledge Network. 2014. Available online: https://knowledge.autodesk.com/search-result/caas/CloudHelp/cloudhelp/ENU/BPA-Help/files/ GUID-DDF449B0-058E-465C-AFF4-7E45917B08EF-htm.html (accessed on 31 March 2019).

66. Fegade, S.L.; Tande, B.M.; Cho, H.; Seames, W.S.; Sakodynskaya, I.; Muggli, D.S.; Kozliak, E.I. Aromatization of Propylene Over Hzsm-5: A Design of Experiments (Doe) Approach. Chem. Eng. Commun. 2013, 200, 1039-1056. [CrossRef]

67. Wang, J.; Wan, W. Kinetic models for fermentative hydrogen production: A review. Int. J. Hydrogen Energy 2009, 34, 3313-3323. [CrossRef]

68. National Institute of Standards and Technology (NIST SEMATECH). e-Handbook of Statistical Methods. 2006. Available online: https://www.itl.nist.gov/div898/handbook/ (accessed on 12 October 2018).

69. Montgomery, D.C. Introduction to Statistical Quality Control, 6th ed.; John Wiley \& Sons: Hoboken, NJ, USA, 2009.

70. Taylor, J.R. Experimental Errors and Uncertainty. Measurement. 2002, 2000-2002. Available online: http://www.ece.rochester.edu/courses/ECE111/error_uncertainty.pdf (accessed on 16 April 2019).

71. The Minitab Blog. Regression Analysis Tutorial and Examples. Minitab 18. 2013. Available online: http://blog.minitab.com/blog/adventures-in-statistics-2/regression-analysis-tutorial-and-examples (accessed on 25 September 2018).

72. Abdulla, R.; Jrade, A. Integrating building information modeling and life cycle assessment tools to design. In Proceedings of the 29th International Conference of CIB W, Beirut, Lebanon, 17-19 October 2012.

73. Autodesk. Getting Started with Autodesk Green Building Studio. Autodesk®EcotectTM Analysis. 2011, 17. Available online: http://images.autodesk.com/adsk/files/Getting_Started_with_Green_Building_Studio_4.3. pdf (accessed on 16 April 2019).

74. Minitab®18 Support. What Is a Main Effects Plot? 2017. Available online: https://support.minitab.com/en-us/ minitab/18/help-and-how-to/modeling-statistics/anova/supporting-topics/basics/what-is-a-main-effects-plot/ (accessed on 22 November 2018).

75. Van der Merwe, M. The Importance of External Walls in Energy Efficiency of Buildings; University of the Free State: Bloemfontein, South Africa, 2012.

76. Badiee, A. The Impact of Roofing Material on Building Energy Performance. The University of Alabama at Birmingham; 2015. Available online: http://adsabs.harvard.edu/abs/2015PhDT........28B (accessed on 16 April 2019).

77. Alibaba, H. Determination of optimum window to external wall ratio for offices in a hot and humid climate. Sustainability 2016, 8, 187. [CrossRef]

78. Peel, M.C.; Finlayson, B.L.; McMahon, T.A. Updated world map of the Köppen-Geiger climate classification. Hydrol. Earth Syst. Sci. 2007, 11, 1633-1644. [CrossRef]

79. Friedman, J.P.; Harris, J.C.; Diskin, B.A. Real Estate Handbook; Barrons Educational Series: Hauppauge, NY, USA, 2005; 764p.

80. Griffin, C.W.; Fricklas, R. Manual of Low-Slope Roof Systems: Fourth Edition; McGraw-Hill: New York, NY, USA, 2006; 598p.

81. European Commission. Innovative Chemistry Builds Energy Efficiency into Smart Cities; ACS: Washington, DC, USA, 2015.

82. Collins, L.M.; Dziak, J.J.; Li, R. Design of Experiments with Multiple Independent Variables: A Resource Management Perspective on Complete and Reduced Factorial Designs. Psychol. Methods 2009, 14, 202-224. [CrossRef]

83. Autodesk Revit. About Green Building Studio and Energy Analysis. Autodesk Knowledge Network. 2017. Available online: https://knowledge.autodesk.com/support/revit-products/learn-explore/caas/CloudHelp/ cloudhelp/2016/ENU/Revit-Analyze/files/GUID-7948A714-1B97-4176-A942-D99A8ECA4786-htm.html (accessed on 22 October 2018). 
84. Suman, B.M.; Srivastava, R.K. Influence of thermal insulation on conductive heat transfer through roof ceiling construction. J. Sci. Ind. Res. 2009, 68, 248-251.

85. Nizam, R.S.; Zhang, C.; Tian, L. A BIM based tool for assessing embodied energy for buildings. Energy Build. 2018, 170, 1-14. [CrossRef]

(c)

(C) 2019 by the authors. Licensee MDPI, Basel, Switzerland. This article is an open access article distributed under the terms and conditions of the Creative Commons Attribution (CC BY) license (http://creativecommons.org/licenses/by/4.0/). 